\title{
'Intravenous' Cannulation: Always Assumed; Rarely Verified; Sometimes Dangerous - A Case Report
}

\author{
Arunabha Karmakar, Glen Fernandes, Tripiti Sinha and Neeraj Kumar* \\ Department of Anesthesia, Perioperative Medicine and Intensive Care, Qatar
}

Submission: March 28, 2018; Published: April 16, 2018

*Corresponding author: Arunabha Karmakar, Department of Anesthesia, Perioperative Medicine and Intensive Care, Hamad Medical Corporation, Post Box 3050, Doha, Qatar, Tel: +974-33227548; Email: Arunabha.Karmakar@gmail.com

\begin{abstract}
We report a case of a baby boy who inadvertently received $4 \mathrm{ml}$ of propofol intra-arterially for sedation. The only warning sign was excessive crying followed by hyperemia and blanching of the limb. Management was immediate cessation of injection and follow up. While the child did not have permanent damage, we highlight the possible error of assuming the correct site of a pre-existing intravenous line and propose a mandatory confirmation of intravenous line placement when transferring care.
\end{abstract}

Keywords: Arterial cannulation; Accidental intra-arterial injection

\section{Introduction}

a. Propofol, an ubiquitous anesthetic induction agent, is commonly known to cause pain on intravenous injection. This is so common that most anesthestists have either learnt to overlook the short lived cry of agony before the patient sleeps or try to 'pre-alleviate' this pain by various recipes including slow infusion, pre-injection with lidocaine or using a fast saline flow as a carrier fluid.

b. Our case exemplifies that sometimes the blame may not rest on propofol alone. With permission from our institutional review board and medical research center, who granted us a waiver of patient consent, we wish to share a case report of an accidental injection of Propofol to a mistakenly placed and therefore mis-labelled intra-arterial line in a baby boy for sedation.

\section{Case Details}

a) A 22 month old boy was admitted in the pediatric surgical unit for unexplained proximal myopathy, dysphagia for solid foods and seizures. He was posted for an urgent diagnostic MRI of the Brain under sedation. As planned, he had arrived in the MRI Suite with his parents and the ward nurse with a pre-placed 24G IV cannula on the ventral aspect of his right wrist through which he had already received about $50 \mathrm{ml}$ of maintenance fluid at $40 \mathrm{ml} /$ hour through an infusion pump. After the handover, we prepared to medicate the child for sedation. b) Following protocol we attached the standard American Society of Anesthesiologists prescribed monitors, and began injecting the child with propofol through the aforementioned iv line. The child cried out sharply with exceptional pain and we immediately noticed some hyperemia of the arm followed by blanching. We stopped injecting immediately ( $4 \mathrm{ml}$ injected) and checked placement of the IV cannula, suspecting thrombophlebitis. We noticed there wasn't free flow of fluids and bright red blood could be freely aspirated from the cannula. We thus suspected Intra-arterial injection and stopped any further injections. A new 22G IV cannula was placed in the dorsum of the left foot and sedation using IV propofol was conducted without any complications.

c) After MRI, we escorted him to the recovery room where $\mathrm{ABG}$ analysis confirmed arterial placement of the $24 \mathrm{G}$ right wrist cannula. The Right Upper Limb was monitored for an hour. Most of the blanching subsided spontaneously. Further follow up of the child did not suggest any pain or discomfort in the arm.

\section{Discussion}

A. While describing the effects of thiopental injected arterially, Dr. Hrant $\mathrm{H}$ Stone et al. [1] succinctly stated in 1961 "Inadvertent injection into an artery, though rare, it is an ever present danger, as long as drugs are administered intravenously". Almost 50 years later, our case and others remind us that patients are vulnerable to iatrogenic injury and 
the opportunity for inadvertent harm cannot be overlooked even in the most unlikely settings [2]. Being anesthetists, we had been conditioned to accept pain on propofol injection as a routine rather than an exception.

B. We thus propose that a severely painful response to any injection should not be overlooked and inadvertent intraarterial injection (or any wrong site injection for that matter) be considered strongly among other possibilities such as wrong drug, wrong dose, wrong site or some underlying disease.

C. Intra-arterial propofol injection has been documented in various case reports and the universal signs had been extreme pain, hyperemia and blanching of the limb [3]. One report suggested that even under General Anesthesia, the pain can be severe enough to cause an increased heart rate and indeed was the first indicator of arterial injection of propofol [4]. Other drugs such as Thiopentone have been known to cause necrosis when injected intra arterially [1]. Another case report described accidental intra-arterial injection of rocuronium, a muscle relaxant used commonly by anesthetists.

D. These cases not only highlight the individual effects of the drugs but remind us that errors are possible in medical practice. Any drug may be given intra arterially by accident. Many previous publications have described why accidental arterial cannulation may occur, what perhaps is to be done if a drug is administered by this line, and added detailed descriptions of clinical features when it occurred. While our case was similar clinically to those previously described, we would add that such incidents be considered as a combination of two separate errors: Wrong intravenous cannulation [5]; and failure to verify the correct placement of the IV cannula after transfer of care. While most analyses of critical incidents would normally focus on the first error, the solution to the issue would be better conceived by examining the second error.
Indeed in anesthesiology practice, repeated verification plays a key role in patient safety. For example correct endotracheal tube placement is immediately confirmed by four separate findings including direct laryngoscopic visualization of the tube passing between the vocal cords, observance of fogging in the tube with expiration, chest auscultation for air entry and finally a capnogram. Perhaps if we exhibited similar vigilance with our cannulas, we may be able to identify such problems early on and prevent similar incidents. In short, be careful with an IV line [6], it may be a medical emergency.

\section{Acknowledgements relating to this Article}

a. Assistance with the article: None.

b. Financial support and sponsorship: None.

c. Conflicts of interest: None.

d. Presentation: None.

\section{References}

1. Stone HH, Donnelly CC (1961) THE ACCIDENTAL INTRA-ARTERIAL INJECTION OF THIOPENTAL. The American Society of Anesthesiologists 22(6): 995-1006.

2. Sen S, Chini EN, Brown MJ, Lundy J, Post C Van der, et al. (2005) Complications After Unintentional Intra-arterial Injection of Drugs: Risks, Outcomes, and Management Strategies. Mayo Clin Proc 80(6): 783-795.

3. Kjaergaard M, Rovsing ML (2010) [Accidental intra-arterial propofol injection]. Ugeskr Laeger 172(18): 1383-1384.

4. Mitani S, Ishiyama T, Matsukawa T (2009) Inadvertent intraarterial injection of propofol in a patient under general anesthesia. J Anesth 23(2): 307.

5. Dennis A, Thies KC (2011) Accidental arterial cannulation in a child. Anaesthesia 66(7): 626-626.

6. Prabhu R, Shenoy R, Thinda N, Patel A, Sadhu S (2014) Be Careful with an IV Line. J Clin Diagn Res 8(3): 166-167.

\section{Your next submission with Juniper Publishers} will reach you the below assets

- Quality Editorial service

- Swift Peer Review

- Reprints availability

- E-prints Service

- Manuscript Podcast for convenient understanding

- Global attainment for your research

- Manuscript accessibility in different formats

( Pdf, E-pub, Full Text, Audio)

- Unceasing customer service

Track the below URL for one-step submission

https://juniperpublishers.com/online-submission.php 